\title{
Physicochemical Properties and Antimicrobial Performance of Benzyldimethylalkylammonium Bis(2-ethylhexyl) Phosphate
}

\author{
Hajime Katano*, Hisashi Kimoto, Shu Taira and Toshihide Tsukatani ${ }^{1}$ \\ Department of Bioscience, Fukui Prefectural University, Eiheiji-cho, Fukui 910-1195, Japan \\ 'Research and Development Division, Nicca Chemical Co., Ltd., Bunkyo, Fukui 910-8670, Japan
}

(Received December 22, 2014; accepted January 21, 2015)

Key words: ionic liquid, antimicrobial agent, surfactant, benzyldimethylalkylammonium, bis(2ethylhexyl) phosphate

Benzyldimethylalkylammonium salts with bis(2-ethylhexyl) phosphate maintain their liquid state at room temperature. These are immiscible but can be dispersed stably in water. The benzyldimethyltetradecylammonium salt emulsion exhibited the highest antimicrobial activity among them and some advantages as an additive for aqueous media compared with conventional cationic-surfactant-type antimicrobial agents.

\section{Introduction}

Benzyldimethylalkylammonium [BA $n^{+}$, Fig. 1(a)] halides have been considered to be one of the safest antimicrobial agents and have a long history of efficacious use. ${ }^{(1,2)}$ The conventional $\mathrm{BA} n^{+}$salts are solid at room temperature and are soluble in water. In a previous paper, ${ }^{(3)}$ we reported that the $\mathrm{BA} 14^{+}$salt with a bis(2-ethylhexyl) phosphate [BEHP' ${ }^{-}$, Fig. 1(b)] anion maintains its liquid state even at room temperature and is immiscible in water. BA14BEHP can be dispersed stably, and the BA14BEHP emulsion exhibited an antimicrobial performance.

In this study, BA $n$ BEHPs with different $n$ values $(=10,12,14,16$, and 18$)$ were prepared, and their physicochemical properties and antimicrobial performance were mutually compared. The physicochemical properties of BAnBEHPs, such as the glass transition temperature, viscosity, conductivity, density, and solubility of water, did not vary significantly with $n$. On the other hand, the minimum inhibitory concentrations (MICs) of BAnBEHP against a gram-positive bacterium, Staphylococcus aureus IFO012732, and a gram-negative bacterium, Escherichia coli CK111, were lowest with $n=12$ and 14 . The MICs of BA12BEHP and BA14BEHP were the same as that of BA14Cl.

${ }^{*}$ Corresponding author: e-mail: hajime@fpu.ac.jp 
<smiles>CCCCCC(C)(C)[N+](C)(C)Cc1ccccc1</smiles>

(a)<smiles>CCCCOP(=O)([O-])OCCC(CCC)CCCC</smiles>

(b)

Fig. 1. Chemical structures of (a) $\mathrm{BA} n^{+}$cation and (b) $\mathrm{BEHP}^{-}$anion.

Various types of antimicrobial materials have been the subject of research interest by some analysts. ${ }^{(4-7)}$ In contrast to conventional cationic-surfactant-type antimicrobial agents such as $\mathrm{BA} 14 \mathrm{Cl}, \mathrm{BA} n \mathrm{BEHPs}$ exhibited a low foaming property. Such a lowfoaming cationic-surfactant-based antimicrobial agent seems to be promising for aqueous media such as cooling water or water-based cutting fluid. ${ }^{(8)}$ The aqueous media usually contain calcium carbonate scale control agents such as polyacrylic acid sodium salt $(\mathrm{PAAS})^{(9)}$ and copper corrosion inhibitors such as $1 H$-benzotriazole (BTA). Thus, the influence of the additives on the antimicrobial performance of BA14BEHP has been studied. Also, the influence of BA14BEHP on the scale control by PAAS has been studied. Although conventional cationic-surfactant-type agents associate with anionic polymers to form colloidal particles, ${ }^{(10)}$ BA14BEHP did not affect the scale control of PAAS.

\section{Experimental Methods}

\subsection{Chemicals}

Benzyldimethyltetradecylammonium chloride (BA14Cl, Tokyo Chemical Industry) and bis(2-ethylhexyl) hydrogenphosphate (HBEHP) (Wako Pure Chemical Industries) were used to prepare BA14BEHP as follows: $20 \mathrm{mmol}$ of $\mathrm{BA} 14 \mathrm{Cl}$ and $20 \mathrm{mmol}$ HBEHP were mixed in $200 \mathrm{ml}$ of water. $20 \mathrm{ml}$ of $2 \mathrm{~mol} \mathrm{l}^{-1} \mathrm{Na}_{2} \mathrm{CO}_{3}$ aqueous solution was added slowly to the mixture. The mixture was heated while stirring until the solid substance was dissolved. The stirring was stopped, and then the mixture separated into an oily substance and an aqueous phase. The mixture was transferred to a separating funnel, and the aqueous phase was removed. The resultant crude BA14BEHP was purified by shaking with water several times. BA14BEHP was dried at $80{ }^{\circ} \mathrm{C}$ under $50 \mathrm{mmHg}$ until the water content became $1 \%$ or less. BA14BEHP was confirmed by IR and UV spectra. The BAnBEHPs $(n=10,12,16$, and 18) were obtained in the same manner as BA14BEHP with benzyldimethyldecylammonium chloride (Fluka), benzyldimethyldodecylammonium bromide, benzyldimethylcethylammonium chloride, and benzyldimethylstearylammonium chloride. The last three BA $n^{+}$-salts were obtained from Tokyo Chemical Industry. Polyacrylic acid sodium salt (molecular weight, 2100) and $1 H$-benzotriazole were obtained from Sigma and Wako, respectively. Other chemicals were reagent-grade materials. They were used without further purification. 


\subsection{Apparatus}

The DSC analysis (DSC6220, SII Nanotechnology, Japan) was performed at a heating rate of $10^{\circ} \mathrm{C} \mathrm{min}^{-1}$. Thermogravimetric analysis (TG-50, Shimadzu, Japan) was performed at a heating rate of $10{ }^{\circ} \mathrm{C} \mathrm{min}^{-1}$ under nitrogen flow of $50 \mathrm{ml} \mathrm{min}{ }^{-1}$. A vibro viscometer (A\&D SV-10), a conductivity meter (CM-40V, DKK-TOA, Japan), and a Karl Fischer titrator (AQV-5, Hiranuma Sangyo, Japan) were used for the determination of the viscosity, conductivity, and water content, respectively. The experiments were performed at $25 \pm 1{ }^{\circ} \mathrm{C}$.

\subsection{Antimicrobial test}

The antimicrobial performance of the BA $n$ BEHP emulsion was examined according to the Japanese Pharmacopoeia with $S$. aureus IFO012732 and E. coli CK111. The bacterial cells were grown at $37^{\circ} \mathrm{C}$ with shaking in LB medium and diluted at a density

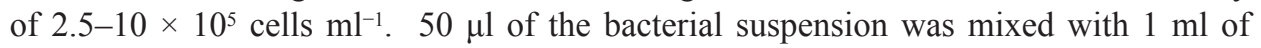
test BA $n$ BEHP emulsion, and then incubated at $25^{\circ} \mathrm{C}$ for $1 \mathrm{~h} .50 \mu \mathrm{l}$ of the mixture was added to $3 \mathrm{ml}$ of super broth, and then the bacterial cells were grown at $37{ }^{\circ} \mathrm{C}$ for $20 \mathrm{~h}$ with shaking. The bacterial growth was examined by visual observation of the degree of turbidity of each culture medium. The antimicrobial test was performed with the $\mathrm{BA} n \mathrm{BEHP}$ emulsion at different weight concentrations to determine the MIC.

\section{Results and Discussion}

\subsection{Physicochemical properties}

The physicochemical properties of the present BAnBEHP are listed in Table 1. The values are in conjunction with those for BA14BEHP prepared with a standard material of benzyldimethyltetradecylammonium chloride (Zephiramine, Dojindo). (3) BA14BEHP did not display a solid-liquid phase transition, but displayed a glass transition in the DSC curve, and the glass transition temperature was determined to be $-8{ }^{\circ} \mathrm{C}$. In thermogravimetric analysis, BA14BEHP exhibited thermal stability up to $c a .210{ }^{\circ} \mathrm{C}$. Thus, BA14BEHP exists in liquid state over a wide temperature range. The viscosity of BA14BEHP was determined to be $4500 \mathrm{mPa} \mathrm{s}$ at $25^{\circ} \mathrm{C}$, which is much higher than those of conventional water-immiscible ionic liquids, such as imidazolium-based ionic liquids and quaternary ammonium salts with bis(perfluoroalkylsulfonyl)imides. ${ }^{(11,12)}$ Also, the

Table 1

Physicochemical properties of BA $n$ BEHP (at $25^{\circ} \mathrm{C}$ ).

\begin{tabular}{lccccc}
\hline$n$ & 10 & 12 & 14 & 16 & 18 \\
\hline Glass transition & -3 & -6 & -8 & -10 & -11 \\
$\quad$ temperature $\left({ }^{\circ} \mathrm{C}\right)$ & 6800 & 4700 & 4500 & 5800 & 3300 \\
Viscosity $(\mathrm{mPa} \mathrm{s})$ & 0.003 & 0.002 & 0.002 & 0.002 & 0.003 \\
Conductivity $\left(\mathrm{mS} \mathrm{cm}^{-1}\right)$ & 0.947 & 0.948 & 0.971 & 0.954 & 0.947 \\
Density $\left(\mathrm{g} \mathrm{ml}^{-1}\right)$ & 25.4 & 19.6 & 18.4 & 12.8 & 12.2 \\
Water $\left(\mathrm{wt}^{\%}\right)$ & & & & & \\
\hline
\end{tabular}


conductivity was $0.002 \mathrm{mS} \mathrm{cm} \mathrm{cm}^{-1}$, which is much lower than those of the conventional ionic liquids. This result suggests that the interaction between the $\mathrm{BA}_{14}{ }^{+}$cation and the BEHP $^{-}$anion is strong. A BA14BEHP-water mixture (1:1 volume ratio) was shaken at $25{ }^{\circ} \mathrm{C}$. The mixture separated into two phases, but both phases emulsified immediately after shaking. The aqueous phase continued to emulsify even several days later. On the other hand, the emulsion particles in the BA14BEHP phase disappeared within $1 \mathrm{~d}$. The solubility of water in BA14BEHP was determined to be $18.4 \mathrm{wt} \%$, which corresponds to the water content of the BA14BEHP phase. This solubility is much higher than that for conventional water-immiscible ionic liquids. ${ }^{(11,12)}$ The high solubility suggests that the phosphate group of the BEHP ${ }^{-}$anion interacts with some water molecules in the BA14BEHP phase. The density of the water-saturated BA14BEHP medium was 0.976 $\mathrm{g} \mathrm{ml}^{-1}$, which is close to that of water. This may be one of the reasons that BA14BEHP can be dispersed stably in water. The median diameter of BA14BEHP particles in the emulsion was determined to be $13 \mu \mathrm{m}$ by a dynamic light scattering particle size analyzer. The foaming property was screened by shaking ten times a $100 \mathrm{ml}$ graduated cylinder containing $30 \mathrm{ml}$ of sample solution. The foam volume of the $400 \mathrm{ppm} \mathrm{BA} 14 \mathrm{Cl}$ solution was 50-60 ml immediately after shaking and 40-50 ml after $10 \mathrm{~min}$. On the other hand, the foam volume of the $400 \mathrm{ppm}$ BA14BEHP emulsion was less than $2 \mathrm{ml}$ immediately after shaking, and the foam disappeared within $10 \mathrm{~min}$.

The physicochemical properties of BAnBEHPs $(n=10,12,16$, and 18$)$ are also listed in Table 1. The glass transition temperature, viscosity, conductivity, density, and solubility of water are in the range of $-11--3{ }^{\circ} \mathrm{C}, 3300-6800 \mathrm{mPa} \mathrm{s}, 0.002-0.003 \mathrm{mS}$ $\mathrm{cm}^{-1}, 0.94-0.96 \mathrm{~g} \mathrm{~cm}^{-3}$, and $12.2-25.4 \mathrm{wt} \%$, respectively. It is noted that the values did not vary much with $n$ in the range tested. The BAnBEHPs can be dispersed also in water, and the emulsions were low-foaming. Therefore, the antimicrobial activity of the $\mathrm{BA} n \mathrm{BEHPs}$ as water additives can be assayed as described below.

\subsection{Antimicrobial performance}

The antimicrobial performance of BA $n$ BEHPs against $S$. aureus IFO012732 and $E$. coli CK111 was assayed at $20 \mathrm{~h}$ contact. The MICs are listed in Table 2. Among the BA $n$ BEHP's tested, BA12BEHP and BA14BEHP yielded the lowest MICs against the bacteria. The dependence of $n$ on the $\mathrm{MIC}$ is similar to that of $\mathrm{BA} n \mathrm{Cl}$ in an aqueous solution..$^{(1,2)}$ The MICs of BA12BEHP and BA14BEHP against the gram-positive bacterium $S$. aureus IFO012732 are lower than those against the gram-negative bacterium $E$. coli CK111. This result is also similar to that of BA14Cl. For comparison, we also assayed tetra- $n$-hexylammonium and tetra- $n$-octylammonium salts with the BEHP

Table 2

Minimum inhibitory concentration (MIC in ppm) of BAnBEHP and BA14Cl against S. aureus IFO012732 and E. coli CK111.

\begin{tabular}{lrrrrrl}
\hline & \multicolumn{5}{c}{ BAnBEHP } & \multirow{2}{*}{ BA14C1 } \\
\cline { 2 - 6 } & $n=10$ & 12 & 14 & 16 & 18 & \\
\hline S. aureus IFO012732 & 200 & 100 & 50 & 200 & $>1000$ & 100 \\
E. coli CK111 & 1000 & 200 & 400 & 1000 & $>1000$ & 400 \\
\hline
\end{tabular}


anion, which can be dispersed in water. They did not kill the bacteria even at $1000 \mathrm{ppm}$. This result suggests that the antimicrobial effect of BA $n$ BEHP's is mainly attributed to the action of the $\mathrm{BA} n^{+}$cation. The $\mathrm{BA} 14^{+}$salt with bis(2-ethylhexyl) sulfosuccinate anion also maintains its liquid state even at room temperature. ${ }^{(3)}$ The BA14BEHP analogue is also water-immiscible and can be dispersed in water. However, the emulsion could not kill the bacteria even at $1000 \mathrm{ppm}$, indicating that the counter anion influences the antimicrobial action of the water-insoluble BA14 ${ }^{+}$salts. The contact efficiency of the BA14BEHP emulsion particles to the bacterial cells is considered to be much lower than that of dissolved BA14Cl species; nevertheless, the MICs of BA14BEHP are the same as those of $\mathrm{BA} 14 \mathrm{Cl}$. Thus, although the mechanism of the antimicrobial action is not clear at present, the experimental results indicate that BA12BEHP and BA14BEHP can be used as antimicrobial agents advantageously for aqueous media. In the following, the applicability of BA14BEHP for cooling water or water-based cutting fluid is discussed.

\subsection{Influence of scale control agent and corrosion inhibitor}

Since aqueous media usually contain calcium carbonate scale and copper corrosion inhibitors, the antimicrobial activity of BA14BEHP against $S$. aureus IFO012732 and $E$. coli $\mathrm{CK} 111$ was assayed also in the presence of $100 \mathrm{ppm}$ BTA and 500 ppm PAAS. The MICs are listed in Table 3. Because $100 \mathrm{ppm}$ BTA and/or $500 \mathrm{ppm}$ PAAS solution in the absence of BA14BEHP did not kill the bacteria, the antimicrobial effect of the mixture is attributed to the action of BA14BEHP. The MICs of BA14BEHP in the presence of 100 ppm BTA are about the same as those in the absence of additives.

The MICs of BA14BEHP in the presence of 500 ppm PAAS seem to be lower than those in the absence of additives. One of the reasons for the effect of PAAS may be the decrease in the size of BA14BEHP particles to enhance the contact efficiency to the bacterial cells. Using a microscope, 10-20 $\mu \mathrm{m}$ BA14BEHP particles were mainly observed in $400 \mathrm{ppm}$ BA14BEHP emulsion, and 1-5 $\mu \mathrm{m}$ BA14BEHP particles were observed in the presence of $500 \mathrm{ppm}$ PAAS. The decrease in particle size was observed also by the addition of $\mathrm{KCl}$ at $1 \mathrm{~mol} \mathrm{l}^{-1}$, suggesting that the particle size depends on ionic atmosphere.

\subsection{Influence on calcium carbonate scale control}

A $250 \mathrm{ppm}\left(\right.$ as $\left.\mathrm{CaCO}_{3}\right) \mathrm{Ca}\left(\mathrm{HCO}_{3}\right)_{2}$ solution was prepared by mixing $250 \mathrm{ppm} \mathrm{CaCl}_{2}$ and $250 \mathrm{ppm} \mathrm{NaHCO}_{3}$. The $\mathrm{pH}$ was adjusted to 8.5 with $\mathrm{NaOH}$ or $\mathrm{HCl}$. The solution was stored at $60{ }^{\circ} \mathrm{C}$ for $20 \mathrm{~h}$ to form the $\mathrm{CaCO}_{3}$ scale according to the reaction:

$$
\mathrm{Ca}\left(\mathrm{HCO}_{3}\right)_{2} \rightarrow \mathrm{CaCO}_{3}+\mathrm{CO}_{2}+\mathrm{H}_{2} \mathrm{O}
$$

Table 3

MICs (in ppm) of BA14BEHP and BA14Cl against S. aureus IFO012732 and E. coli CK111 in the presence of 100 ppm BTA and 500 ppm PAAS.

\begin{tabular}{lccccc}
\hline & \multicolumn{2}{c}{ BAnBEHP } & & \multicolumn{2}{c}{ BAnCl } \\
\cline { 2 - 3 } \cline { 5 - 6 } & BTA & PAAS & & BTA & PAAS \\
\hline S. aureus IFO012732 & 100 & 20 & & 100 & 100 \\
E. coli CK111 & 200 & 100 & & 200 & 100 \\
\hline
\end{tabular}


Then, the reaction mixture was cooled to room temperature and centrifuged. The concentration of $\mathrm{Ca}^{2+}$ species in the supernatant $\left(c_{\mathrm{Ca}}\right)$ was determined to be $80 \pm 30$ ppm by spectrophotometry with Arsenazo-III. Anionic polymers, such as PAAS and polyphosphoric acid, can control the $\mathrm{CaCO}_{3}$ scale formation by association with the $\mathrm{Ca}^{2+}$ ion to form water-soluble $\mathrm{Ca}^{2+}$-polyanion complexes. ${ }^{(8,9)}$ The $c_{\mathrm{Ca}}$ obtained with the 250 ppm $\mathrm{Ca}\left(\mathrm{HCO}_{3}\right)_{2}$ solution containing 500 ppm PAAS was $250 \pm 10 \mathrm{ppm}$, indicating that the $\mathrm{CaCO}_{3}$ scale formation shown by eq. (1) is controlled successfully by PAAS. The $c_{\mathrm{Ca}}$ obtained with the $250 \mathrm{ppm} \mathrm{Ca}\left(\mathrm{HCO}_{3}\right)_{2}$ solution containing $500 \mathrm{ppm}$ PAAS and $400 \mathrm{ppm}$ BA14BEHP was determined to be $250 \pm 10 \mathrm{ppm}$, indicating that BA14BEHP did not affect the scale control by PAAS. Similarly, it was shown that BA14BEHP did not affect the scale control by polyphosphoric acid. Interestingly, the $c_{\mathrm{Ca}}$ obtained with the 250 $\mathrm{Ca}\left(\mathrm{HCO}_{3}\right)_{2}$ solution containing $400 \mathrm{ppm}$ BA14BEHP was $230 \pm 5 \mathrm{ppm}$, suggesting that BA14BEHP can inhibit the formation of the $\mathrm{CaCO}_{3}$ scale as well as organophosphorus compounds. The effect may be attributed to the adsorption of $\mathrm{BEHP}^{-}$on the fine particles of $\mathrm{CaCO}_{3} \cdot{ }^{(13)}$

\section{Conclusion}

BA14BEHP can be applied as an antimicrobial agent for aqueous media. The antimicrobial test is now being extended to other bacteria.

\section{Acknowledgements}

This work was supported by Grant-in-Aids from the Ministry of Education, Science, Sports and Culture of Japan (No. 26410226).

\section{References}

1 R. S. Shelton, M. G. V. Campen, C. H. Tilford, H. C. Lang, L. Nisonger, F. J. Bandelin and H. L. Rubenkoenig: J. Am. Chem. Soc. 68 (1946) 753.

2 K. Jono, T. Takayama, M. Kuno and E. Higashide: Chem. Pharm. Bull. 34 (1986) 4215.

3 H. Katano, M. Akita, H. Tatsumi and T. Tsukatani: Bokin Bobai 35 (2007) 147.

4 J. R. Uzarski and C. M. Mello: Anal. Chem. 84 (2012) 7359.

5 H. Etayash, K. Jiang, T. Thundat and K. Kaur: Anal. Chem. 86 (2014) 1693.

6 L. Wang, J. Luo, S. Shan, E. Crew, J. Yin, C.-J. Zhong, B. Wallek and S. S. S. Wong: Anal. Chem. 83 (2011) 8688.

7 P. A. Fulmer and J. H. Wynne: ACS Appl. Mater. Interfaces 3 (2011) 2878.

8 Z. Amjad: J. Colloid Interface Sci. 123 (1988) 523.

9 Q. Yang, Y. Liu, A. Gu, J. Ding and Z. Shen: J. Colloid Interface Sci. 240 (2001) 608.

10 E. H. Hill, H. C. Pappas and D. G. Whitten: Langmuir 30 (2014) 5052.

11 M. Galiński, A. Lewandowski and I. Stępniak: Electrochim. Acta 51 (2006) 5567.

12 H. Matsumoto, H. Kageyama and Y. Miyazaki: Chem. Lett. 30 (2001) 182.

13 M. Fujiyama and H. Inata: Nippon Kagaku Kaishi 2001 (2001) 289. 